\title{
A descriptive study comparing the surgical outcomes between power- assisted adenoidectomy and conventional surgical methods
}

\author{
Navalakhe M. M. ${ }^{1}$, Mogre D. A. ${ }^{2}$ \\ ${ }^{1}$ Dr. Milind M. Navalakhe, Associate Professor, ${ }^{2}$ Dr. Dilesh A. Mogre, Resident, both authors are affiliated with \\ Department of ENT, B.Y.L. Nair Charitable Hospital and T. N. Medical College, Mumbai Central, Mumbai, India.
}

Corresponding Author: Dr. Milind M Navalakhe, Associate Professor, Department of ENT, B.Y.L. Nair Charitable Hospital and T.N. Medical College, Mumbai Central, Mumbai, India. E-mail: drmilindn@gmail.com, damogre@gmail.com

\begin{abstract}
Objective: To study the surgical outcomes between power assisted and conventional curettage adenoidectomy.And to perform retrospective analysis by comparing the two surgical methods on the basis of duration of surgery, intra-operative blood loss, postoperative complications like bleeding and associated trauma. Design: A retrospective and prospective study of 100 cases was performed in a tertiary care teaching hospital in Mumbai. Over 1 year and 8 months. The mean operative time was faster in conventional method $(\mathrm{p}<0.0001)$. Subjects: 100 cases. Methods: After selection of cases retrospective assessment of peri-operative conditions were obtained from case records duration of surgery, Intraoperative blood loss, Postoperative complications. The same cases were called for prospective analysis data on long-term postoperative outcome was obtained by using 'Paediatric Throat Disorders Outcome Test' Result: Our 100 patients ranged from 4 to 27 years with mean age of 10.43 years with SD of $4.24 \mathrm{~F}$ : M ratio was 1.17. The operative blood loss between two groups was not statistically significant $(\mathrm{p}=0.4901)$. The symptomatic relief after conventional surgery and power assisted method was statistically significant $(\mathrm{p}<0.0001)$. There was no statistical significance between outcomes of both methods. Conclusions: Our study shows that the power assisted adenoidectomy was a safe, well tolerated procedure and an useful tool for adenoidectomy with disadvantages of high cost. Conventional adenoidectomy with a curette is safe, fast and economical. It fails to obtain complete tissue removal and thus is less effective than the power assisted techniques.
\end{abstract}

Keywords: Adenoidectomy; Conventional Curettage; Endoscopic surgical procedure; Power assisted adenoidectomy.

\section{Introduction}

"It is true in every surgical department that our failures cannot fairly be ascribed to the imperfection of our instruments, but rather to the faulty manipulation with which they are applied.' - Dr John Ward Cousins, BMJ, $1905[1]$.

The adenoids, also known as the Luschka's tonsil or the nasopharyngeal tonsil, is a mass of lymphoid tissue located in the roof of the nasopharynx. The adenoids along with the palatine and lingual tonsils are an integral part of the Waldeyer's ring, forming 3 to $5 \%$ of the entire lymphatic system. The adenoids and tonsils, like other lymphoid tissues are known to undergo physiological hypertrophy between the ages of 5 to 11 years. Symptomatic adeno-tonsillar hypertrophy is a

Manuscript received: $20^{\text {th }}$ March 2019

Reviewed: $30^{\text {th }}$ March 2019

Author Corrected: $6^{\text {th }}$ April 2019

Accepted for Publication: $10^{\text {th }}$ April 2019 common disorders in pediatric population and can cause obstructive sleep apnea (OSA), as well as chronic sinusitis and recurrent otitis media. [2]. Adeno-tonsillar obstruction of the nasal airway not responding to conservative management is an indication for surgery.

Adenoidectomy was first performed using a ring knife through the nasal cavity by William Meyer in 1867[3].

Since then the surgical approach to adenoids has evolved in terms of surgical methods, instruments and anaesthesia techniques. Adenoidectomy has been conventionally performed with the curettage method but it is a blind procedure.

Endoscopic Adenoidectomy was popularized by Canon et al. It provides better visualisation of surgical field and prevents damage to surrounding structures [4]. 
The present study aims to evaluate the benefits and the complications of power assisted adenoidectomy and compare it with conventional curettage methods.

\section{Aims and Objectives}

1. To study and compare the surgical outcomes between power assisted and conventional curettage adenoidectomy.

\section{Materials and Methods}

Study Design: Retrospective and Prospective study. Setting: Tertiary care teaching hospital in Mumbai.

Study Period: 1 year and 8 months.

Retrospective analysis from January 2014 to January 2015

Prospective assessment from February 2015 till September 2015

Sample Size: 100 cases

\section{Inclusion Criteria}

Patients who underwent adenoidectomy power assisted or conventional as a part of their treatment in a tertiary care teaching hospital for various reasons like:

A. Chronic adenotonsillitis

B. Lack of response to medical treatment and requiring adenoidectomy.

2. Obtaining written informed consent and informed assent from parents or guardian.

\section{Exclusion criteria}

1. Patients with a history of prior nasal or oral surgery to eliminate pre-existing surgical variables.

2. Unwillingness to give written informed consent and informed assent from parents or guardian.

This study was approved by the institutional ethics committee and was carried out in accordance with the Declaration of Helsinki. A total of 100 consecutive patients who underwent adenoidectomy between January 2014 to January 2015 for chronic adenotonsillitis at a tertiary care teaching hospital as a part of treatment of underlying condition, either with conventional or Power-assisted adenoidectomy using Microdebrider; who were

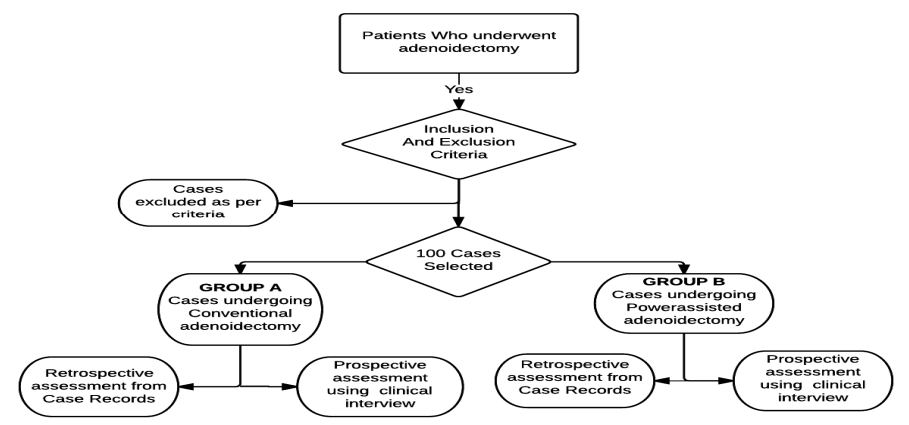

Fig-1: Flow-chart of the study design

similar with respect to age, body mass index (BMI), Grade of adenoid hypertrophy, American Society of Anesthesiologists (ASA) score, were selected to be included in the analysis. Group A consisted of cases undergoing conventional adenoidectomy using curettage method and Group B undergoing power assisted adenoidectomy. 
After selection of cases retrospective assessment of peri-operative conditions were obtained from case records from the Medical Record Office of the institute with due permission. Investigations done as a part of clinical line of management like Anterior and Posterior rhinoscopy, X-ray soft-tissue nasopharynx and diagnostic nasal endoscopy were documented along with observation of duration of surgery, Intraoperative blood loss, Postoperative complications like bleeding and associated trauma if any from case records from medical records with due permission of authorities.

The same cases were called for prospective analysis from February 2015 till September 2015 and study was explained and written informed consent was taken from each patient. Data on long-term postoperative outcome was obtained by using 14-item 'Paediatric Throat Disorders Outcome Test' conducted six months after surgery. The 14-item Paediatric Throat Disorders Outcome Test is an appropriate, disease-specific, parent-reported outcome measure for children with throat disorders [5].

Postoperative surgical outcome for residual disease was evaluated by a diagnostic nasal endoscopy. The adenoid tissue hypertrophy was graded by using Parikh et al classification [6]. As per history, clinical examination and investigations and treatment findings were tabulated and results interpreted.

The data was analyzed using standard statistical packages like Graphpad Prism, Version-6.07 (Trial). Appropriate statistical analysis with a two-tailed t test was performed for data that followed a Gaussian distribution. For data that did not follow a normal distribution appropriate non-parametric test were used. The significance level of $\mathrm{p}<0.05$ was chosen to define statistical significance.

\section{Results}

A total of 100 consecutive patients who underwent adenoidectomy between January 2014 to January 2015 in the department of Otolaryngology at a tertiary health center. Out of these 100 patients, $54 \%$ of the study population were female and $46 \%$ were male with F: M ratio of 1.17.

The study population ranged from 4 to 27 years with mean age of 10.43 years with SD of 4.24 years (95\% CI 9.59 to 11.27 years). The frequency histogram of age distribution in two groups of patients undergoing adenoidectomy with the two surgical methods has been plotted below (Fig.2). It shows a majority of population 49\% lies between the age group of 5 to 10 and years followed by $31 \%$ in between 10 to 15 years. Only $2 \%$ of the population aged more than 25 years of age. There was no statistical difference between the two groups with regard to sex or age $(p>0.5)$.

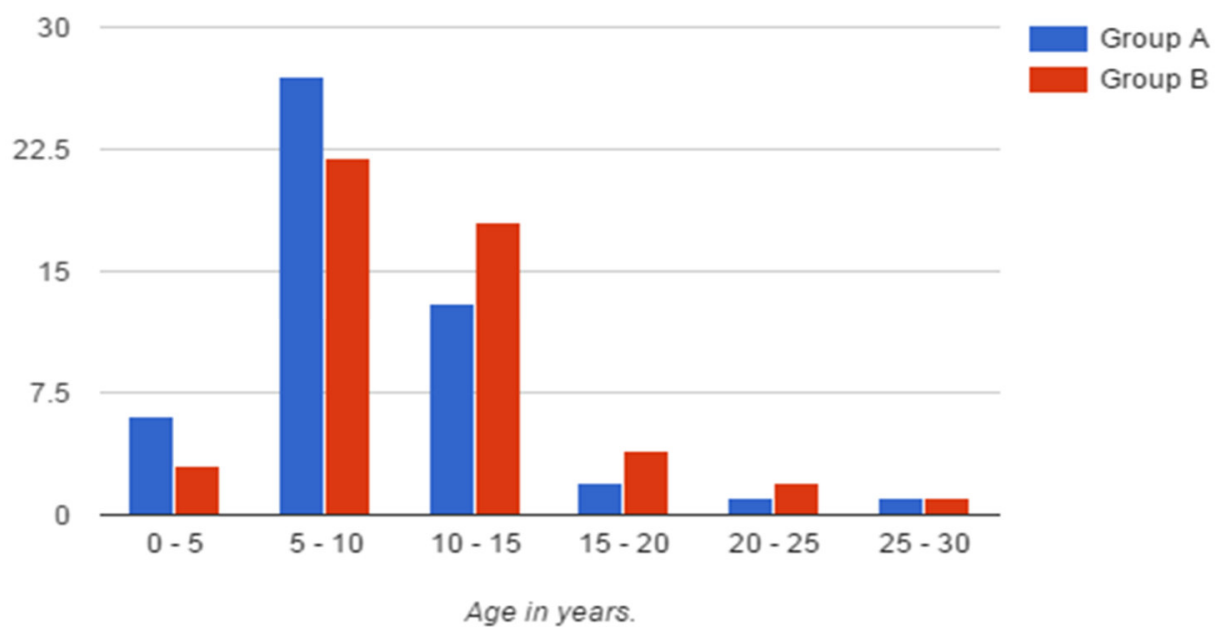

Fig-2: Age distribution of the study population

The operative blood loss was $38.96 \mathrm{ml}$. ( $\mathrm{SD}=4.8895 \%$ CI 37.57 to $40.35 \mathrm{ml})$ in patients undergoing power assisted adenoidectomy, which was almost equal to the $38.32 \mathrm{ml}$. ( $\mathrm{SD}=4.3495 \% \mathrm{CI} 37.09$ to $39.55 \mathrm{ml})$ blood loss seen in cases undergoing conventional curettage method, this difference was not statistically significant $(\mathrm{p}=0.4901)$. 
Group A

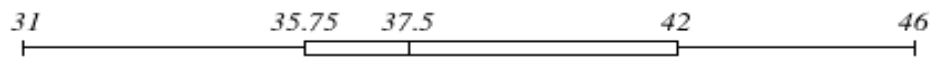

Group B

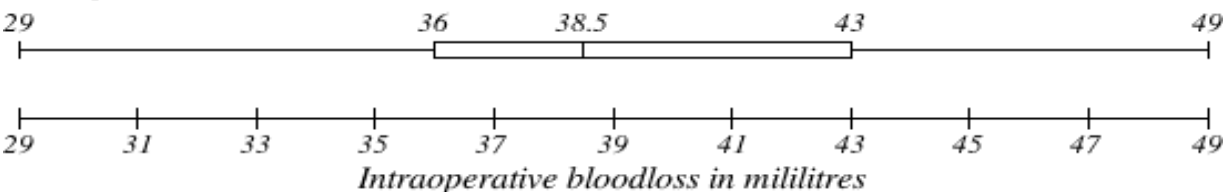

Fig-3: Comparison of intraoperative blood loss

The mean operative time was 10.00 minutes (SD $1.50,95 \%$ CI 9.57 to $10.43 \mathrm{~min}$ )
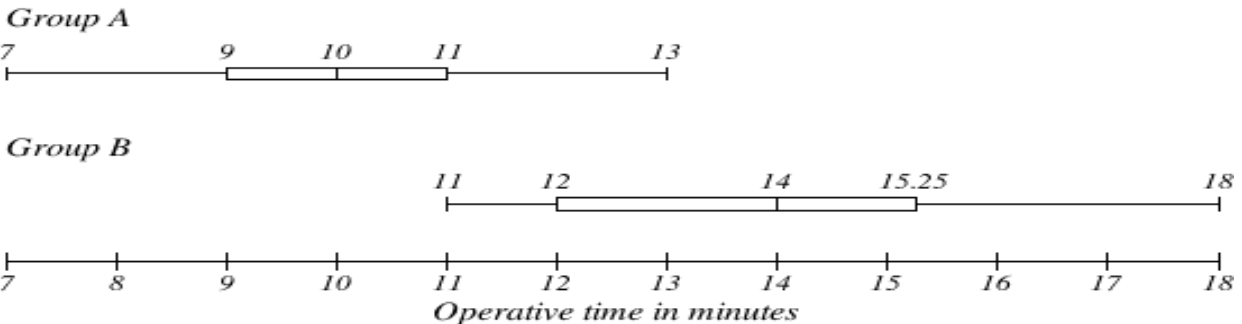

Fig-4: Comparison of Operative time-

for conventional adenoidectomy, which was faster than the 14.08 minutes (SD 1.85 min with $95 \%$ CI 13.55 to $14.61 \mathrm{~min})$ required for power assisted adenoidectomy $(\mathrm{p}<0.0001)$ this difference is considered to be statistically significant by using the two-tailed Unpaired $t$ test and represented graphically in (figure 4).

Comparison of symptomatic relief obtained after surgical intervention was performed by using the 'Paediatric Throat Disorders Outcome Tool' (T-14) questionnaire score. The preoperative T-14 score was compared with postoperative T14 score conducted by interviews completed six months after the surgical intervention.

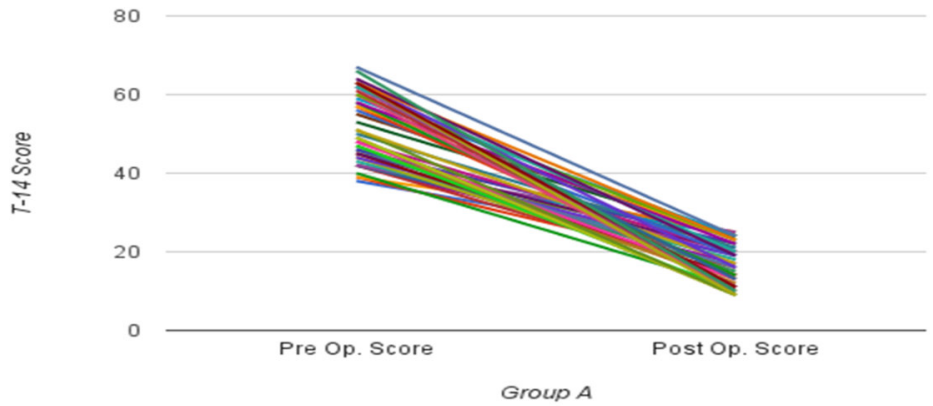

Fig-5: The comparison of preoperative and the 6-month postoperative T-14 scores in Group A.

In the conventional adenoidectomy group, the T-14 score improved from the mean preoperative score of 51.26 (SD 1.85 min with $95 \%$ CI 48.80 to 53.72 ) to the mean postoperative score 6-months after surgery of 17.18 (SD 5.25 with $95 \%$ CI 15.69 to 18.67$)$. The non-parametric Mann-Whitney test showed that the symptomatic relief after conventional surgery was statistically significant $(\mathrm{p}<0.0001)$; and in the power assisted adenoidectomy group, the mean preoperative T-14 score of 49.98 (SD 8.25 with $95 \%$ CI 47.64 to 52.32 ) improved to 17.56 (SD 4.85 with $95 \%$ CI 16.18 to 18.94 ) assessed after the same postoperative period.

The symptomatic relief obtained was statistically significant $(\mathrm{p}<0.0001)$ with Mann-Whitney test. Although both surgical methods achieved symptom relief, 


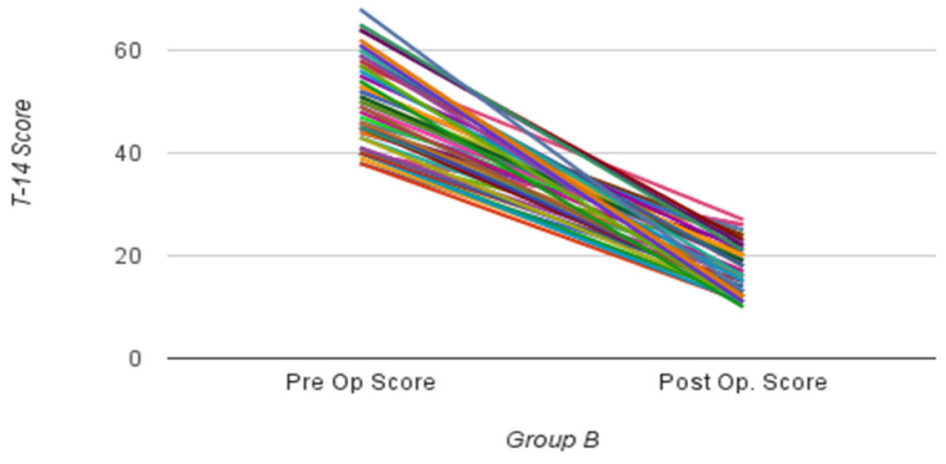

Fig-6: The comparison of preoperative and the 6-month postoperative T-14 scores in Group B.

no statistical significance was found when the postoperative T-14 scores were compared for Groups A and B (p = 0.3669 ) or in the gain of T-14 scores(fig.7).

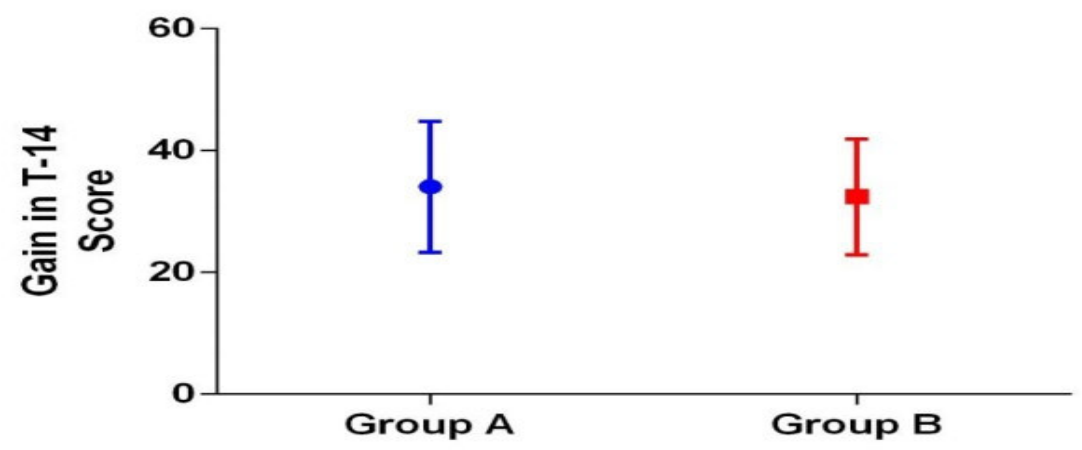

Fig-7: Box plots comparing the gains in T-14 scores of curettage adenoidectomy and power-assisted endoscopic adenoidectomy groups $(P=\mathbf{0 . 4 4 4 4})$

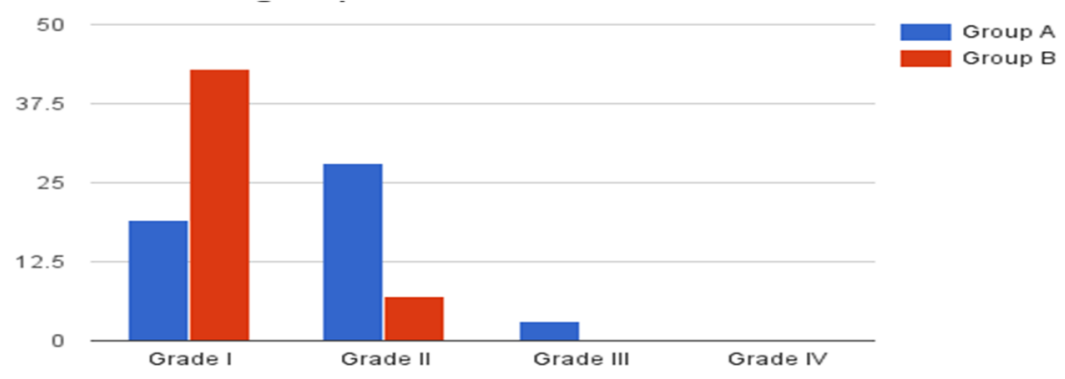

Fig-8: Comparison of residual adenoid tissue at the end of surgical procedure in the two groups

Rigid nasal endoscopy performed at the end of surgical procedure showed that at the end of the procedure $86 \%$ of patients undergoing power assisted adenoidectomy had a no residual adenoid tissue as compared to $38 \%$ of patients underwent conventional resection. Only $14 \%$ of patients undergoing power assisted adenoidectomy had a residual adenoid tissue of Grade II. Whereas $62 \%$ of cases had residual adenoid tissue after undergoing conventional curettage adenoidectomy, 56\% with Grade II and 6\% with Grade III residual tissue. The difference between residual adenoid tissue between two groups is statistically significant by using the Wilcoxon signed-ranks test $(\mathrm{p}<0.0001$.)

No postoperative complications in the form of excessive postoperative bleeding, Eustachian tube scarring, velopharyngeal scarring or atlanto-occipital instability were observed in either groups. 


\section{Discussion}

"I have sometime on more than one occasion assured myself, both by sight and touch of the complete clearance of the post nasal space after operation and yet I have later on noted the gradual regrowth of adenoid tissue sufficient to call for a second operation.... incomplete removal is, unfortunately, not uncommon..." Sir St Clair Thompson, BMJ, 1917 [7].

The post-surgical recurrence of adenoids is described in the literature since the very beginning of its surgical excision. Studies evaluating conventional adenoidectomy have proved that the removal of adenoid tissue is often incomplete. Power assisted adenoidectomy is performed under vision and provides complete resection of adenoid tissue without the risk of injury to the neighboring nasopharyngeal structures. The present study was undertaken to compare the surgical outcomes of power assisted adenoidectomy and conventional adenoidectomy.

The present study as the study population was retrospective randomization could not done. Patients similar with respect to age, body mass index (BMI), Grade of adenoid hypertrophy, American Society of Anesthesiologists (ASA) score, were selected to be included in the analysis. All patients with a history of prior nasal or oral surgery, incomplete preoperative information was excluded from analysis.

Studies have concluded that adenoid hypertrophy is common in children. Pagella et al studied a cohort of 795 pediatric patients and showed that adenoid hypertrophy was more common in patients with allergy sensitization, in particular in patients aged 8-14 years. They also demonstrated a significant association among pathological adenoid hypertrophy, age, and nasal obstruction [8]. Only $2 \%$ of the study population was above the age of 25 years.

The incidence of adult adenoid hypertrophy is uncommon but increasing, because of allergy, chronic infection, pollution and rarely malignancy [9]. There was no statistical difference between the two groups with regard to sex or age $(P>0.5)$.

The mean operative time for conventional adenoidectomy in the present study was 10.00 minutes, while power assisted adenoidectomy took an average of 14.08 minutes. The difference is considered to be statistically significant $(\mathrm{p}<0.0001)$. The assessment of the operative time included all the steps for performing powered assisted surgery including time taken for packing and decongestion of nose with cottonoids soaked in lignocaine and adrenaline, resection of adenoid tissue and securing haemostasis. As a result, the time taken in the present series may seem longer than other studies. According to Al Mazrou et al., 2009; Havas and Lowinger, 2002; a complete adenoidectomy with a microdebrider was shown to be faster than a traditional curettage adenoidectomy. Recent review evidenced that operative time required for complete adenoid tissue resection using the microdebrider takes around 5 to 6minute. [10,11] Koltai et al. and Rodriguez et al. performed the adenoidectomy with a microdebrider under an indirect visualization using a laryngeal mirror, it was shown to be faster than a traditional curettage adenoidectomy[12,13].

According to Dutta et al, the microdebrider is potentially a dangerous instrument which should be used under direct and close vision as that provided through an endoscope [14]. Since the parameters used to define operative time differ in different studies, the duration of the surgical procedure are difficult to compare. However, the present study shows that the power assisted adenoidectomy consumes more time.

Our study means intraoperative blood loss for both surgical methods was around $38 \mathrm{ml}$. This is similar to the intraoperative blood loss findings reported by Bradoo et al[15]. The series by Feng et al showed that blood loss was more in the conventional adenoidectomy group though the difference between the groups was not statistically significant [16]. Stanislaw et al however, has reported a significant reduction in blood loss following endoscopic adenoidectomy [17]. The microdebrider provides an advantage of a wellcontrolled dissection reaching to a lesser vascular plane of nasopharynx, thus reducing the amount of bleeding.

This shortens the time required for hemostasis. Intraoperative bleeding during any transnasal endoscopic procedure is challenging. The microdebrider provides an efficient suction-irrigation set up and secures well-controlled resection under clear endoscopic view [18]. In the restricted area of a child's nose, the surgeon has to manage complete surgical clearance and manage problems such as bleeding. The most bloodless approach to perform endoscopic power assisted adenoidectomy is to start resection high from the choana and progress in an orderly fashion to the inferior border of the adenoid bed, with the cutting tip of the microdebrider in continuous view[19]. 


\section{Original Research Article}

Studies have proved that conventional curettage adenoidectomy, does not achieve adequate removal of obstructive adenoid tissue in upto one-third of cases. The factors preventing complete adenoid tissue resection in conventional curettage method is the presence of intranasal extension of the tissue, or a bulky adenoids superiorly in the nasopharynx and in the peritubal region [20].

The results of our study show that resection was invariably incomplete with the curettage method. Only $38 \%$ of cases in Group A had complete adenoid resection as compared to $86 \%$ of cases undergoing power assisted adenoidectomy. The degree of adenoid tissue hypertrophy was estimated using the grading system proposed by Parikh et $\mathrm{al}^{60}[6]$. Our study showed that only $14 \%$ of patients undergoing power assisted adenoidectomy had a residual adenoid tissue. All the cases in Group A had residual adenoid tissue of Grade II at the end of the procedure. Whereas, $62 \%$ of patients undergoing conventional curettage surgery had residual adenoid tissue. $56 \%$ of group A patients had Grade II residual adenoids and $6 \%$ with Grade III residual tissue.

The difference between two groups was shown to be statistically significant by using Mann-Whitney test $(p<0.0001)$. In the study by Ark et al. Reported that only one-fifth of the patients undergoing curettage adenoidectomy had no residual adenoid tissue. Instead, $81 \%$ of the patients a residual lymphatic tissue was still present on the pharyngeal roof and near the choana. $11.4 \%$ of the patients had a residue along the torus tubarius on either side of the nasopharynx and in $6.3 \%$ the residual tissue was located at both cited sites [21].

Factors affecting the surgical outcomes of conventional curette adenoidectomy are the extension of adenoid tissue into the choana and the rounded contour of roof and posterior wall of the nasopharynx which does not match the perfectly cutting edge of the curette. In power assisted adenoidectomy, the curved blade properly fits into the nasopharynx. The use of endoscopic visualization of the nasopharynx provides excellent illumination and focus which optimizes precision in the removal of adenoid tissue. The power assisted technique, resection of residual adenoid tissue around the choana, posterior part of the nasal passage and torus tubarius is well executed.

Minimizing the risk of injury to the neighboring nasopharyngeal structures and pharyngeal muscles. The complete resection provided by power assisted adenoidectomy results in a better chance of resolving any disease process related to the presence of adenoid tissue [22]. Any residual adenoid tissue has the potential to hypertrophy, which may subject the patient to the recurrence of symptoms, and eventually the need for revision surgery. This study has shown that power assisted adenoidectomy decreases the risk of recurrence of residual adenoid hypertrophy and provides completeness to the surgical procedure of adenoidectomy.

The Comparison of symptomatic relief obtained after surgical intervention was performed by using the 'Paediatric Throat Disorders Outcome Tool' (T-14) questionnaire score. The preoperative score was compared with the postoperative score based on interviews completed six months after the surgical intervention. The difference between preoperative and postoperative scores was considered significant $(p>0.0001)$. However, the difference in postoperative scores comparing the outcomes of power assisted and conventional adenoidectomy was not statistically significant. Similar findings have been reported by Öztürk, in their study [23]. The difference between the pre and postoperative scoring of symptoms in the two groups did not reach statistical significance, because an adenoid mass becomes symptomatic only when more than approximately $50 \%$ of the postnasal space has been obstructed [24].

Our study does not report damage to nasopharyngeal structures following adenoidectomy. However there is always a fear of trauma to the torus tubarius especially in curettage method leading to subsequent scarring and eustachian tube dysfunction. In power assisted adenoidectomy, there is an increased risk of nasal mucosal injuries.

The use of rigid endoscope has its advantages like good visualization which ensures complete removal of adenoid tissue situated in hard to reach areas of the nasopharynx without damaging surrounding structures. When adenoidectomy is performed transnasally there is no need to extend the neck especially in patients with instability of cervical spine [25]. The camera attachment allows for magnified view, facilitating recording as well as training.

The recognized disadvantage of power-assisted adenoidectomy is the increased patient charge associated with the use of disposable instrumentation. The elimination of pathological review of routine adenoid specimens, as the specimens are too traumatized to provide the microscopic detail necessary to make diagnosis. This may provide a means of off setting the increased charge by $62 \%$ [26]. Learning to 


\section{Original Research Article}

pass both the scope and debrider blade through the narrow paediatric nose presents a challenge to the novice. As with any new surgical technique, there is a learning curve to endoscopic-assisted adenoidectomy, Initially, the surgery appears to take more time but results demonstrate a trend toward decrease in the time of the procedure with experience; Bradoo et al[15].

The Indian scenario presents a situation where availability of the equipment is also a factor in choosing the method of surgery. Though nasal endoscopes are fast becoming basic tools, powered instrumentation like micro-debriders are still not commonly found in many setups [14].

This study draws attention towards key aspects in the surgical management of adenoid hypertrophy. Endoscopic surgery has become an integral part of Otolaryngology and thus endoscopic power assisted adenoidectomy is a natural evolution of this technology.

\section{Conclusion}

In our study, the method of power assisted adenoidectomy was a safe, well tolerated procedure and an useful tool for adenoidectomy. It has advantages of completeness of resection, accurate removal, less collateral damage, lesser postoperative pain and faster recovery.

The disadvantages of power-assisted adenoidectomy are the high cost and inability to provide good quality tissue for histopathological diagnosis. Conventional adenoidectomy with a curette is safe, fast and economical. Though it is a blind procedure, it may achieve the desired symptom relief in many patients.

However, it fails to obtain complete tissue removal and thus is less effective than the power assisted techniques.

Acknowledgements-We thank our Dean Dr R. N. Bharmal for his constant support and encouragement.

\section{Funding: Nil, Conflict of interest: Nil \\ Permission from IRB: Yes}

\section{References}

1. Cousins JW. The Treatment Of Post-nasal Adenoids. British Medical Journal. 1905;1(2305):514.

2. Scadding G. Non-surgical treatment of adenoidal hypertrophy: the role of treating IgE-mediated inflammation. Pediatr Allergy Immunol. 2010 Dec; 21 (8): 1095-106. doi: 10.1111/j.1399-3038.2010.01012.x.
3. Robb Peter J. Scott-Brown's Otorhinolaryngology: Head and Neck Surgery. $7^{\text {th }}$ Ed : CRC Press; 2008: 1094-1101.

4. Cannon CR, Replogle WH, Schenk MP. Endoscopicassisted adenoidectomy. Otolaryngol Head Neck Surg. 1999 Dec;121(6):740-4

5. Hopkins C, Fairley J, Yung M, Hore I, Balasubramaniam S, Haggard M. The 14-item Paediatric Throat Disorders Outcome Test: a valid, sensitive, reliable, parent-reported outcome measure for paediatric throat disorders. The Journal of Laryngology \& Otology. 2010 Mar;124(3):306-14.

6. Parikh SR, Coronel M, Lee JJ, et al. Validation of a new grading system for endoscopic examination of adenoid hypertrophy. Otolaryngol Head Neck Surg. 2006 Nov; 135(5):684-7.

7. Thomson S. Recurrence Of Adenoids And Tonsils. British Medical Journal. 1917; 2 (2960): 400-401.

8. Pagella F, De Amici M, Pusateri A, et al. Adenoids and clinical symptoms: Epidemiology of a cohort of 795 pediatric patients. Int J PediatrOtorhinolaryngol. 2015 Dec; 79(12): 2137-41. doi: 10.1016/j.ijporl. 2015.09. 035. Epub 2015 Oct 8.

9. Rout MR, Mohanty D, Vijaylaxmi Y, et al. Adenoid Hypertrophy in Adults: A case Series. Indian J Otolaryngol Head Neck Surg. 2013 Jul; 65 (3): 269-74. doi: 10. 1007/ s12070-012-0549-y. Epub 2012 Mar 29.

10. Al-Mazrou, KA; Al-Qahtani, A \& Al-Fayez AI. (2009). Effectiveness of transnasal endoscopic powered adenoidectomy in patients with choanal adenoids. International Journal of Pediatric Otorhinolaryngology, Vol. 73, No.12, pp. 1650-1652.

11. Havas T, Lowinger D. Obstructive adenoid tissue: an indication for powered-shaver adenoidectomy. Arch Otolaryngol Head Neck Surg. 2002 Jul; 128 (7): 789-91.

12. Koltai PJ, Kalathia AS, Stanislaw P, et al. Powerassisted adenoidectomy. Arch Otolaryngol Head Neck Surg. 1997 Jul;123(7):685-8.

13. Rodriguez, K; Murray, N \&Guarisco, JL. Powerassisted partial adenoidectomy. Laryngoscope, 2002; 112: (8) Pt.2 Suppl.100, pp. 26-28. 


\section{Original Research Article}

14. Datta R, Singh VP, Deshpal. Conventional Versus Endoscopic Powered Adenoidectomy: A Comparative Study. Med J Armed Forces India. 2009 Oct;65(4):30812. doi: 10.1016/S0377-1237(09)80089-0. Epub 2011 Jul 21.

15. Bradoo, Renuka A., et al. Comparison of Endoscopic-AssistedAdenoidectomy with Conventional Method. An International Journal Clinical Rhinology 4.2 (2011): 75-78.

16. Feng Y, Yin S. [Comparison of the poweredassisted adenoidectomy with adenoid curette adenoidectomy]. Lin Chuang Er Bi Yan Hou Ke Za Zhi. 2006 Jan;20(2):54-7.

17. Stanislaw P Jr, Koltai PJ, Feustel PJ. Comparison of power-assisted adenoidectomy vs adenoid curette adenoidectomy. Arch Otolaryngol Head Neck Surg. 2000 Jul; 126(7):845-9.

18. Vokurka J. Shaver (micro debridor) in otorhinolaryngology. International Congress Series. 2003; 1240:1411-15.

19. Inancli HM, Enoz M. Odds and evens for endoscopic adenoidectomy. Acta Otorhinolaryngol Ital. 2009 Feb;29(1):51; author reply 51-2.

20. Elluru, RG, Johnson L, Myer CM. Electrocautery adenoidectomy compared with curettage and powerassisted methods. Laryngoscope, 2002;Vol.112, No.8 Pt. 2 Suppl.100, pp. 23-25.
21. Ark N, Kurtaran H, Ugur KS, et al. Comparison of adenoidectomy methods: examining with digital palpation vs. visualizing the placement of the curette. Int J Pediatr Otorhinolaryngol. 2010 Jun;74 (6): 649-51. doi: 10. 1016/j. ijporl. 2010. 03.012. Epub 2010 Apr 3.

22. Costantini F, Salamanca F, Amaina T, Zibordi F. Videoendoscopic adenoidectomy with microdebrider. Acta Otorhinolaryngol Ital. 2008;28:26-9.

23. Öztürk Ö, Polat Ş. Comparison of transoral powerassisted endoscopic adenoidectomy to curettage adenoidectomy. Adv Ther. 2012 Aug;29 (8): 708-21. doi: $\quad$ 10.1007/s12325-012-0036-6. Epub 2012 Jul 31.

24. Kemaloglu YK, Goksu N, Inal E, et al. Radiographic evaluation of children with nasopharyngeal obstruction due to the adenoid. Ann Otol Rhinol Laryngol. 1999 Jan; 108 (1): 67-72.

25. Havas T, Lowinger D. Obstructive adenoid tissue: an indication for powered-shaver adenoidectomy. Arch Otolaryngol Head Neck Surg. 2002 Jul; 128 (7): 789-91.

26. Gillespie, M. B., Ingram, F., Scarlett, M., \& Hoy, M. Value-based approach to power-assisted adenoidectomy. Annals of Otology, Rhinology \& Laryngology 2003; 112(7), 606-610.

How to cite this article?

Navalakhe M. M, Mogre D. A. A descriptive study comparing the surgical outcomes between power-assisted adenoidectomy and conventional surgical methods. Trop J Ophthalmol Otolaryngol.2019;4(2):71-79. doi:10.17511/jooo.2019.i02.02 